\title{
"I'm Sure She Chose Me!" Accuracy of Children's Reports of Mothers' Favoritism in Later Life Families*
}

\author{
J. Jill Suitor
}

\author{
Jori Sechrist
}

\author{
Michael Steinhour
}

\author{
Karl Pillemer**
}

\begin{abstract}
We used data from 769 mother-child dyads nested within 300 later life families to explore the accuracy of adult children's perceptions of mothers' patterns of favoritism in terms of closeness and confiding. Adult children were generally accurate regarding whether their mothers preferred a specific child, but often had difficulty identifying whom mothers favored. Multivariate analyses indicated that overall accuracy of children's reports was positively related to similarity of religious participation and negatively related to parental status of the adult child and family size. Because parental favoritism may affect adult children psychologically and have implications for later life care for parents, family practitioners should be aware of mothers' patterns of favoritism and the sometimes inaccurate perceptions adult children have concerning this favoritism.
\end{abstract}

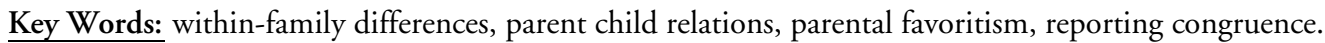

Discrepancies in parents' and children's reports of intergenerational affect and interaction patterns have long been recognized among family scholars (Aquilino, 1999; Bengtson \& Kuypers, 1971; Giarrusso, Stallings, \& Bengtson, 1995; Pruchno, Burant, \& Peters, 1994). With few exceptions (Aquilino; Rossi \& Rossi, 1990), studies of parents and adult children have conceptualized these discrepancies as a general tendency emanating from the differential generational stake of parents and children (Bengtson \& Kypers; Giarrusso et al., 1995). This line of research has focused on differences in reports of intergenerational affect and support between the generationsfor example, whether parents report greater intergenerational closeness and support exchange than do their adult children. Researchers have not, however, thus far attempted to explain why some pairs of parents and children report greater consistency than do others regarding socioemotional dimensions of their relationships. One question of particular interest not addressed in the scholarly literature is whether adult children are aware of the patterns of parents' favoritism that exist in many later life families (Suitor \& Pillemer, 2006).

Identifying and explaining within-family variations in parent-child agreement have both theoretical and practical implications. First, although much is known about within-family differences in parent-child relations in the early stages of the life course, only recently has attention been directed toward later life families. This work has shown that most mothers favor some children over others in terms of emotional closeness and exchange of both instrumental and emotional support (Suitor \& Pillemer, 2006; Suitor, Pillemer, \& Sechrist, 2006). However, there has been no exploration of whether

\footnotetext{
*This project was supported by a grant from the National Institute on Aging (RO1 AG18869-01), J. J. S. and K. P., Coprincipal Investigators. K. P. also acknowledges support from an Edward R. Royal Center grant from the National Institute on Aging (1 P30 AG022845). We wish to thank Jane T. Pillemer, Rebecca Powers, and Scott L. Feld for their helpful comments on earlier drafts of the article. We want to thank Michael Bisciglia, Rachel Brown, Ilana S. Feld, Alison Green, Kimberly Gusman, Jennifer Jones, Dorothy Mecum, Michael Patterson, and Monica Shackelford for their assistance in preparing the data for analysis and participating in the analysis of the qualitative data. We would also like to thank Paul Allison for his helpful suggestions regarding the data analysis. Finally, we thank Mary Ellen Colten and her colleagues at the University of Massachusetts, Boston, for collecting the data for the project.

**J. Jill Suitor is a Professor of Sociology in the Department of Sociology, and Anthropology and Center on Aging and the Life Course at Purdue University, Stone Hall, 700 W State Street, West Lafayette, IN 47907 (jsuitor@purdue.edu). Jori Sechrist is a Doctoral Student in the Department of Sociology, and Anthropology and Center on Aging and the Life Course at Purdue University, 700 W State Street, West Lafayette, IN 47907 (sechristj@purdue.edu). Michael Steinhour is a Doctoral Student in the Department of Sociology, and Anthropology and Center on Aging and the Life Course at Purdue University, 700 W State Street, West Lafayette, IN 47907 (msteinho@purdue.edu). Karl Pillemer is a Professor in Human Development, MVR Hall, Cornell University, Ithaca, NY 14850 (kap6@cornell.edu).
} 
adult children are aware of such patterns of favoritism. Studying these patterns will shed new light on intergenerational congruence by documenting the ways in which such agreement varies within families in later phases of the life course. Given that consensus among family members has played a central role in the development of some of the most influential theoretical perspectives in family studies (Bengtson \& Roberts, 1991; Silverstein \& Bengtson, 1997), understanding these processes is particularly important.

Second, studying within-family variations in perceptions of relationship quality has potential implications for clinicians who work with older individuals and their families. Research is needed to increase understanding of support processes in later life families. Studies of informal social support during health crises has demonstrated that individuals are more likely to receive appropriate aid when there is a high level of consensus between care recipients and caregivers (Burg \& Seeman, 1994; Martire, Stephens, Druley, \& Wojno, 2002). Thus, documenting the conditions under which parents and adult children share perceptions regarding their relationship may help to identify which adult children are likely to be the most reliable source of support to their parents. Further, family systems approaches often rely on uncovering and reconciling family members' divergent perspectives. It is useful to understand this kind of "multiperspectivity" and the degree to which it follows predictable patterns (King \& Wynne, 2004). Finally, perceived parental favoritism is an issue that causes distress for many offspring (Cleese \& Bates, 2003) and is likely to arise in therapeutic situations. Thus, shedding light on the degree to which this phenomenon occurs and is perceived accurately may assist clinicians who work with adult children and older parents.

To address these issues, we compared the reports of 769 mother-child dyads nested within 300 later life families regarding emotional closeness and confiding. We address two primary research questions. First, to what extent do adult children accurately report their mothers' patterns of emotional closeness and confiding within the family? That is, to what degree can adult children accurately report whether their mothers differentiate among their offspring by choosing a child whom they prefer? Second, which characteristics of adult children and of motherchild dyads predict agreement between mothers' and children's reports of which child is preferred?

\section{Similarity, Empathy, and Reporting Accuracy}

To our knowledge, there is no research specifically addressing factors that predict the accuracy of adult children's assessments of parental preference. Although a small number of empirical studies have examined parent-child reporting congruence in the younger years (cf. Alessandri \& Wozniak, 1987; Tein, Roosa, \& Michaels, 1994; Youngblade \& Shenkman, 2003), the findings from these studies provide few insights regarding concordance in later stages of family life. An alternative body of theory and research is available from the literature on the effect of similarity and empathy on social networks and relationships across the life span, which we suggest is more useful than relying on the literature on concordance with parents when offspring are children or young adults. This perspective has been used effectively in understanding the quality of relationships between older parents and adult children (Suitor, Pillemer, \& Keeton, 1995).

Similarity is important in understanding the development and maintenance of relationships throughout the life course (cf. Feld, 1982; Lazarsfeld \& Merton, 1954; McPherson, Smith-Lovin, \& Cook, 2001; Suitor, Pillemer, \& Keeton, 1995; Wellman \& Wortley, 1990). Drawing upon theories of role structure and reference groups, scholars in this tradition have argued that individuals are more likely to develop and maintain supportive relationships with others who are similar to them on important dimensions; this is because individuals who share social statuses tend to hold similar values and are more knowledgeable about one another's circumstances, resulting in greater empathy and understanding (cf. Coser, 1991; Lazarsfeld \& Merton; Suitor, Pillemer, \& Keeton, 1995; Wellman \& Wortley). In this article, we are concerned primarily with those dimensions of similarity for which there is theoretical and empirical support regarding empathy-similarity of gender, values, educational attainment, and maturational level.

\section{Gender}

The theoretical literature on gender and empathy suggests that this dimension of similarity would be especially important in explaining the accuracy with which role partners report one another's affect. 
Scholars such as Chodorow (1978) and Gilligan (1982) have argued that women are especially sensitive to others' emotions, a pattern expected to result in greater ability to perceive accurately role partners' feelings. Further, these perceptions of increased empathy and understanding play an especially important role in discussions of differences in mothers' relationships with daughters versus sons (Arcana, 1981; Nice, 1992). Support for this position was provided in a recent study of within-family differences in intergenerational relations that found that mothers reported greater emotional closeness to daughters than sons specifically because they believed that their daughters were more sensitive to their feelings than were their sons (Suitor \& Pillemer, 2006). Empirical studies of parent-child agreement in the younger years provide no consistent picture regarding the effects of gender similarity (Cashmore \& Goodnow, 1985; McBroom, Reed, Burns, Hargraves, \& Trankel, 1985); however, on the basis of the strong theoretical arguments just presented, we hypothesized that daughters' reports of their mothers' favoritism would be more consistent with the mothers' reports than would sons' reports.

\section{Similarity of Values}

The literature suggests that two forms of similarity are especially salient in explaining interpersonal relations-similarity of general values or perspectives and religious similarity. Further, educational similarity is important for interpersonal relationships because of its effect on values and attitudes (Pascarella \& Terenzini, 1991).

Similarity of outlook. As discussed above, both theoretical arguments and empirical investigations have identified similarity of values as a cornerstone of interpersonal relationships (cf. Lazarsfeld \& Merton, 1954; Suitor, Pillemer, \& Keeton, 1995; Wellman \& Wortley, 1990). The literature on kin relations has demonstrated that such similarity is also central to understanding intergenerational solidarity and affection (Bengtson, 2001; Silverstein \& Bengtson, 1997; Wellman \& Wortley). In particular, parents tend to report higher levels of closeness and lower levels of conflict with adult children to whom they are more similar (Suitor \& Pillemer, 2006; Welsh \& Stewart, 1995). On this basis, we hypothesized that adult children who shared their mothers' outlook would be more likely to accurately report their mothers' favoritism regarding emotional closeness and confiding.
Religious similarity. Religious similarity, particularly similarity of participation, has been found to positively influence the quality of parent-adult child relationships, as well as increasing the likelihood of assistance from adult children to parents (Myers, 2004; Pearce \& Axinn, 1998). Further, religious attendance positively affects consensus in parentadult child dyads (Aquilino, 1999; Rossi \& Rossi, 1990). Therefore, we hypothesized that adult children whose church attendance patterns are similar to their mothers will be more likely to report their mothers' favoritism accurately.

Educational similarity. Both classic and contemporary literature on adult interpersonal relationships has shown educational attainment to be a particularly important dimension of similarity (cf. Gouldner \& Strong, 1987; Lazarsfeld \& Merton, 1954; Suitor \& Keeton, 1997). One of the primary reasons for this is that individuals who share the same educational level tend to hold the same values (Pascarella $\&$ Terenzini, 1991; Suitor \& Keeton) thus promoting empathy. Educational discrepancies have an effect on parents' and children's understanding of one another. Although parents generally feel pride when their children surpass them educationally, they often experience concern because the educational disparity reduces their ability to understand one another's feelings (Suitor, 1987; Ryff, Schmutte, \& Lee, 1996). Thus, we hypothesized that adult children who were educationally similar to their mothers would be more likely to provide accurate reports of their mothers' favoritism.

\section{Children's Maturation}

Children's maturation, both chronologically and socially, has been found to be important in predicting empathy between parents and adult children. The most important factor in this process, from a sociological standpoint, is that children come to share a greater number of social statuses with their parents across the life course. As both Thoits (1986) and Suitor, Pillemer, and Keeton (1995) have argued, such status similarity enhances experiential similarly, which plays a key role in the development of empathy. Thus, it is not surprising that as children become older, they are more likely to take their parents' perspectives (Suitor, Pillemer, Keeton, \& Robison, 1995). On these bases, we posit that both children's age and children's attainment of normative adult statuses, such as marriage, parenthood, 
and employment, will be associated with greater reporting congruence regarding mothers' favoritism.

In summary, we hypothesized that the dyads in which children would be most likely to report accurately their mothers' favoritism regarding emotional support and confiding would be those in which dyad members were similar in terms of gender, outlook, religious participation, and education. Further, we hypothesized that reports would be more accurate when children were older and had achieved normative adult statuses.

It is important to reiterate that throughout all of the analyses, our focus was on within-family differences - in other words, we hypothesized that the characteristics of individual children and of mother-child dyads, relative to those of other children and dyads in the family, would explain differences in reporting agreement. For example, whether an adult child accurately reports which offspring the mother favors will depend not only on his or her educational similarity to the mother but also on his or her educational similarity relative to that of other adult children in the family.

\section{Methods}

\section{Design Goals}

We designed this project to provide data on withinfamily differences in parent-adult child relations in later life. The research design involved selecting a sample of mothers $65-75$ years of age with at least two living adult children and collecting data from mothers regarding each of their children. A further decision was to include community-dwelling mothers in the sample to reduce the likelihood that the women would be in need of extensive caregiving, thus, allowing us to study relationships outside of the context of caregiving.

\section{Sampling}

Massachusetts city and town lists were the source of the sample. Massachusetts requires communities to keep city/town lists of all residents by address. Town lists also provide the age and gender of residents. With the assistance of the University of Massachusetts, we drew a systematic sample of women aged 65 - 75 from the town lists of 20 communities in the greater Boston area. An equal number of women in the target age group were selected from each community. We then sent a letter of introduction to each woman describing the study and explaining that an interviewer would contact her from the Center for Survey Research to determine her eligibility for participation and attempt to schedule a face-toface interview if she met the study criteria.

The design called for interviewing 550 mothers. The interviewers began contacting potential respondents and continued until they had reached the target number of cases. Because interviews were conducted simultaneously by several individuals, a slightly larger number of interviews was completed than originally planned. Between August 2001 and January 2003, interviewers collected data from 566 mothers, which represented $61 \%$ of those who were eligible for participation.

At the end of each interview, the interviewers told the mothers about the study component involving adult children and asked if they would provide contact information for their children. Approximately $70 \%$ of the mothers agreed to provide information, and approximately $70 \%$ of the children agreed to participate. We completed interviews with at least one child in 300 families, resulting in a sample of 773 adult children. We then conducted telephone interviews with the children; using this procedure allowed us to maintain a single mode of data collection despite the fact that many of the children lived in distant parts of the country. Interviews with the children were conducted between January 2002 and August 2003. The present analysis uses data from interviews with the 300 mothers whose children participated in the study and the 769 adult children on whom we have complete data. Interviews with the mothers took between 1 and $2 \mathrm{hr}$; each of the children interviews lasted for approximately $40 \mathrm{~min}$. More than 90\% of the interviews were audiotaped and fully transcribed. Field notes were prepared for each interview not fully audiotaped.

\section{Sample Characteristics}

Mothers' characteristics. The mothers were between 66 and 78 years of age $(M=70.9, S D=3.2)$ at the time the interviews were conducted. Seventyseven percent were White and 23\% Black. Fifty percent of the mothers were currently married, $38 \%$ were widowed, and $12 \%$ were divorced or separated. Eighteen percent of the mothers had completed less 
than high school, $41 \%$ had completed high school, and $40 \%$ had completed at least some college. Seventy-one percent were not employed; $34 \%$ percent had a total family income of less than $\$ 20,000$ in the previous year, $26 \%$ had an income between $\$ 20,000$ and $\$ 29,999,12 \%$ had an income between $\$ 30,000$ and $\$ 39,999,8 \%$ had an income between $\$ 40,000$ and $\$ 49,999$, and $21 \%$ had an income $\$ 50,000$ or greater. Forty-six percent of the women were Catholic, 45\% were Protestant, 5\% were Jewish, and $4 \%$ reported another religion or indicated no religious affiliation. The number of women's living children ranged from 2 to 13 ( $M=$ $3.8, S D=1.7)$. Although the mean number of living children in this subsample was higher than would be found in a nationally representative sample of women aged $65-75$, it is important to remember that this was due primarily to the criterion that all participants must have at least two living adult children. The mean number of children of women in the subsample was similar to that found in national samples (e.g., Sweet \& Bumpass, 1996), when compared specifically to mothers in the same age group who have two or more children.

Adult children's characteristics. The adult children ranged from 23 to 61 years of age $(M=43.7, S D=$ 5.3). Forty-eight percent were daughters. Sixty percent of the adult children were currently married, $6 \%$ were cohabiting, $14 \%$ were divorced or separated, 19\% were never married, and $2 \%$ were widowed. Seven percent of the adult children had less than a high school education, $28 \%$ had graduated high school, $14 \%$ had completed some college, $32 \%$ were college graduates, and 19\% had completed some graduate work. Eighty-four percent of the children were employed. Seventy-three percent were themselves parents $(M$ number of children $=2.4, S D=1.2)$.

\section{Measures}

\section{Dependent Variables}

We asked the mothers a lengthy series of questions about their relationships with their children. Included in this series of items were questions about which of her children (a) she would be most likely to talk to about a personal problem and (b) to which child she felt the most emotional closeness. Each child was coded as 0 for each item for which he or she was not chosen, and 1 for each item for which she or he was chosen, according to the mothers' reports. Each adult child was asked parallel questions regarding to which offspring their mothers were most emotionally close and to whom they would talk about a personal problem. These responses were then used to assign each offspring in the family a score of 0 or 1 according to each child's report.

We used the combination of the mothers' and children's reports to create two sets of measures of reporting congruence. We began by designing a measure of congruence for each of the two relational contexts-emotional closeness and confiding. First, we created a variable to measure mother-child agreement about whether the mother had named a child to whom she was most emotionally close, or alternatively, had said that she could not choose among them. This variable was coded 1 (mother's and child's reports agreed that she either had or had not chosen a child) or 0 (mother's and child's reports differed regarding whether the mother named a child). A second consistency variable was created that measured whether, among those dyads in which mothers did select a child, the child accurately reported which offspring the mother named. This variable was also coded 1 (mother and child named the same offspring as mother's favorite) or 0 (mother and child named different offspring). The same two variables were created for confiding.

We created a second set of variables designed to measure the extent to which adult children's reports accurately reflected their mothers' reports. For these variables, we summed the number of instances in which the adult child accurately reported the preferences stated by his or her mother. The first measure summed the number of times the adult child was correct in his or her reports concerning whether the mother had reported favoring a child for either emotional closeness or confiding. Thus, the range of scores could vary from 0 (child was never accurate) to 2 (child was accurate for both emotional closeness and confiding). The second measure summed the number of times the child was correct about which specific child the mother had named; the range of scores for this measure was also $0-2$. Finally, we computed a measure of child's accuracy across both whether the mother differentiated and what specific child she named. This measure ranged from 0 (child was never accurate) to 4 (child was correct about both whether the mother had differentiated and which child she had chosen for both relational contexts). 
Independent Variables-Similarity

Outlook. Perceived similarity of outlook, considered from the perspective of the mothers, was measured by the item: "Parents and children are sometimes similar to each other in their views and opinions and sometimes different from each other. Would you say that you and [child's name] (4) share very similar views, (3) similar views, (2) different views, or (1) very different views in terms of general outlook on life?" An identical question was asked of the adult children regarding the extent to which they felt they shared their mothers' outlook. Rather than creating an aggregate measure, both mothers' and children's reports were included in the analysis. These two measures were correlated only at .24; thus, including them both did not introduce collinearity.

Religious participation. To measure similarity of religious participation, both mothers and their adult children were asked whether they attended religious services: (1) rarely or never, (2) less than once a month, (3) one to three times monthly, (4) once a week, or (5) more than once a week. Because the mothers' scores were clustered at the high end of the scale and children's scores were clustered at the low end, we collapsed the categories to create dichotomies for both variablesmore than once a month and less than once a month. Similarity was measured by whether the mother and child participated in religious services with the same frequency (using the collapsed categories).

Education. Educational similarity was created using a combination of mothers' and children's educational attainment. Mothers were asked into which educational category their own education and that of each of their adult children fell: (1) less than high school, (2) some high school, (3) high school graduate, (4) post-high school vocational, (5) some college, (6) college graduate, or (7) completed graduate school. The categories were collapsed into less than high school, high school, or at least some college. A dichotomous variable was created indicating whether the mother and child had completed the same level of education $(0=$ not similar, $1=$ similar level of education $)$.

Gender. Child's gender was coded $0=$ son, $1=$ daughter. Because mothers were the only parent respondents, this coding of gender indicated gender similarity between the mother and adult child.

\section{Maturational Characteristics}

Child's age was measured in years, as taken from the mothers' reports. Employment status was based on mothers' reports of whether each child (1) was employed or (0) was not employed. Martial status and parental status are both salient normative adult social structural positions; however, it was not possible to include them both because they were strongly correlated (.50). We chose to include parental status because the literature has traditionally shown it to be associated with experiential similarity, affect, and support exchange (Fischer, 1986). Adult children were coded 1 if they were parents and 0 if they were not.

\section{Controls}

We controlled on several dyad-level and family-level characteristics throughout the multivariate analyses. Frequency of contact was measured by the question "How often do you talk with [child's name] on the telephone-(7) every day, (6) several times a week, (5) at least once a week, (4) $2-3$ times a month, (3) about once a month, (2) less than once a month, or (1) never?" We also included a measure of family history of favoritism because the literature demonstrates that patterns of family relations from earlier years are often carried over when children reach adulthood (Bedford, 1992; Rossi \& Rossi, 1990). We asked each adult child whether his or her mother had attempted to be fair to him or her, and whether his or her mother had "tended to play favorites" when the respondent was a child. We constructed a measure of favoritism in childhood by adding the values on the two items, resulting in a measure that ranged from two to eight.

The family-level characteristics on which we controlled were race and family size. We included these factors because we previously found them to be predictors of mothers' likelihood of differentiating among her children regarding emotional closeness and confiding (Suitor et al., 2006). Race was coded as (1) Black or (0) White. Family size was measured by the number of living children in the family, as reported by the mother.

\section{Statistical Approach to Studying Within-Family Differences}

Analyses were conducted to determine the rates of agreement between mothers and their adult children and to test for significance of congruence. We used kappa and chi-square values to indicate significant congruence between mothers and children's 
reports. Chi-square values were calculated to test the significance of congruence of specific child choice because the range of values differed for mothers and children; Kappas require that the values be the same. For example, for confiding, mothers named up to their 9th-born children, whereas the children named up to the 10th-born children.

Throughout the analysis explaining patterns of within-family differences, the child, rather than the parent, was the unit of analysis. In other words, the 769 children who were the units of analysis were nested within the 300 mothers on whose reports the present analysis was based; thus, the observations were not independent. To address this concern, we used binary logistic regression with robust standard errors and Ordinary Least Squares (OLS) regression with robust standard errors to correct for dependence among children in the same family. This approach allowed us to take into consideration family-level as well as child- and dyad-level factors (Maas \& Hox, 2004; Szinovacz \& Davey, 2001).

\section{Open-Ended Responses}

Our goals in using qualitative data in the present article were to understand mothers' rationale for the choices they made when selecting among offspring and to understand why adult children felt that particular offspring were favored by their mothers. To this end, at each point at which mothers were asked to choose from among their children, we included an open-ended question asking why they had selected that child. In the adult child interviews, we did not follow up each favoritism question with an open-ended prompt; however, many children provided explanations without such a prompt. The data that are most relevant to the present article were the adult children's explanations for why particular children were named as those to whom mothers were most close and to whom they would turn for confiding.

\section{Results}

\section{Patterns of Consistency in Reporting Favoritism}

Sixty-eight percent of the mothers reported that they were emotionally closer to one of their children, and $84 \%$ named a particular child in whom they confided when facing a personal problem. Children were more likely than the mothers to report that their mothers favored some children over others in the family. Eighty-four percent of the adult children reported that their mothers were emotionally closer to a particular child, and $92 \%$ reported that there was a child to whom their mothers would be most likely to turn in the face of a personal problem.

The adult children were not, however, completely accurate in their reports of mothers' preference for one child over others in the family. Only $66 \%$ of the children accurately reported that their mothers had chosen a child to whom she was most emotionally close $(\kappa=.06, \alpha=n s)$. There was more consistency in reports of mothers' choice for confiding- $82 \%$ of the children accurately reported that the mothers had chosen a child $(\kappa=$ $.69, \alpha=.00)$.

The next question we addressed was whether, in families in which mothers had chosen specific offspring, adult children could accurately report which child was favored. The adult child respondents were substantially less accurate in reporting which particular child in the family was favored, compared to whether mothers chose any child. Only $44 \%$ of the children accurately reported which offspring the mother identified as her choice for most emotionally close, and only $58 \%$ accurately reported to which specific child the mother reported she turned to talk about personal problems. Nevertheless, the congruence between mothers and children was still statistically significant for both emotional closeness and confiding $\left(\chi^{2}=459.58, \alpha=.00\right.$, and $\chi^{2}=547.14$, $\alpha=.00$, respectively).

We expected that children who accurately reported that their mothers favored some children in the family would be more confident in their reporting than those whose reports were not accurate. However, this was not the case. In fact, children who were inaccurate often displayed great confidence in their reports. This was particularly the case when children thought their mothers chose them, but they had not:

\section{That would be me!}

I'd have to say me, because I think we're the closest out of the others. So, I'll be selfish and say myself.

[I know she is closest to me because] she calls me before anyone else. She depends on me. 
Further, offspring whose mothers favored other offspring were often confident that their mothers did not report any favoritism:

Well [Mom] always says equal so I don't know how to answer that one.

I think she feels [very emotionally close] about all of us ... She's always made it clear that she, we're all treated equally. All our lives, she's said that.

We're all pretty equal ... My parents don't have favorites. We're all treated the same. We really are all treated the same.

In contrast, offspring who correctly reported being selected by the mother often showed hesitancy regarding their perceptions:

I mean we certainly share a lot of [closeness]. The closest though-gee that's hard to say. You know how your time is when you are together, [but] you don't know exactly how it is when you're not. She and I are very close.

That's very hard to say. I don't know. Maybe me, because I have children and [my sister] doesn't.

I think she's close to all of us emotionally but maybe a little more to me.

In summary, the majority of mothers were willing to name an adult child to whom they were most emotionally close and to whom they were most likely to talk about personal problems. Further, most adult children recognized that their mothers made these sorts of preferential choices among the siblings. However, when it came to identifying the preferred child, only about half of the children correctly reported the offspring to which their mother was most emotionally close or to whom the mother would turn to as a confidant. Finally, although it would be reasonable to expect that children chosen by their mothers would be more confident in their reports, the qualitative data suggest otherwise. Children who were chosen were sometimes less certain of their mothers' favoritism than were children who were not their mothers' favorites.

\section{Explaining Congruence in Mothers' and Children's Choices}

To explain consistency in mothers' and children's reports, we began by conducting a set of binary logistic regression analyses. These analyses allowed us to explore what characteristics differentiated between children who did and who did not accurately report their mothers' choices. On the basis of our conceptual framework, the predictors included gender, similarity of outlook, similarity of religious participation, educational similarity, child's age, parental status, and employment. Race, family size, frequency of contact between mother and child, and child's perceptions of favoritism in childhood were included as controls.

We began by exploring the factors that predicted which children in the family were the most likely to accurately report that their mothers had named a favorite child for emotional closeness or confiding regarding personal problems. Contrary to expectations, none of the variables included in the analyses was related to the accuracy of the child's report that the mother had a preference (data not shown). We conducted a subsequent analysis to examine whether children could identify the specific offspring whom their mother preferred. Similar to the initial analysis, this analysis revealed no systematic patterns. In other words, no characteristics predicted which children could identify the specific offspring to whom mothers felt most emotionally close and in whom they would prefer to confide (data not shown).

We believe that the absence of clear patterns reflected the fact that the large majority of both mothers and children reported that mothers differentiated among their children for emotional closeness and confiding. Thus, we felt that perhaps a different analytic approach would be more fruitful. Although it is difficult to discriminate between children whose reports agree with those of their mothers in each individual context, we believed it possible to predict which children were the most likely to be correct across contexts. In other words, perhaps characteristics of children whose reports were the most consistently accurate differ from those of children whose reports seldom, or never, accurately reflected their mothers' stated preferences.

To explore this issue, we conducted a series of OLS analyses in which we regressed the summation measures of children's reporting accuracy on the set 
of variables measuring mother-child similarity, children's maturation, contact, favoritism, race, and family size. The findings revealed a clear pattern of which children most accurately reported mothers' stated preferences.

Model 1 of Table 1 presents the findings of the analysis of children's accuracy regarding whether mothers differentiated among their children in terms of either emotional closeness or confiding. Only one child characteristic and one family characteristic predicted which children accurately reported whether their mothers had differentiated. Children who were themselves parents were less likely to accurately report whether their mothers had named particular children as those to whom they were emotionally closest and to whom they would turn as a confidant. Children with a larger number of siblings were more likely to accurately report favoritism.

The second model in Table 1 shows the findings of the analysis of children's accuracy in reporting which children mothers had named. Adult children who were parents were less likely to accurately report which offspring their mothers had chosen for closeness or confiding, consistent with the findings above regarding whether mothers had chosen a child. Children who were similar to their mothers in terms of religious participation were more likely to accurately report which children the mothers had named. Although children in large families were more likely to know whether their mothers had differentiated, they were less likely to know which child she had named.

Finally, the third model in Table 1 presents the findings of the analysis of children's reporting accuracy across both mothers' favoring any child and the specific children whom she favored for both closeness and confiding. These findings mirrored those in the analysis of the children's accuracy regarding which offspring mothers had chosen. Children who were the most likely to accurately report mothers' favoritism regarding differentiation and child choice were those who shared her religious participation,

Table 1. Regression Analysis of Adult Children's Reporting Accuracy Regarding Mothers' Favoritism

\begin{tabular}{|c|c|c|c|c|c|c|}
\hline & \multicolumn{2}{|c|}{ Model $1^{\mathrm{a}}$} & \multicolumn{2}{|c|}{ Model $2^{b}$} & \multicolumn{2}{|c|}{ Model $3^{c}$} \\
\hline & $B$ & $S E B$ & $B$ & $S E B$ & $B$ & $S E B$ \\
\hline \multicolumn{7}{|l|}{ Similarity } \\
\hline Gender & 0.02 & 0.05 & 0.08 & 0.07 & 0.11 & 0.10 \\
\hline Outlook (mother's perception) & 0.02 & 0.03 & 0.02 & 0.04 & 0.02 & 0.05 \\
\hline Outlook (child's perception) & 0.03 & 0.03 & 0.03 & 0.05 & 0.03 & 0.06 \\
\hline Religious participation & 0.05 & 0.05 & $0.13^{\dagger}$ & 0.07 & $0.17^{\dagger}$ & 0.09 \\
\hline Education & 0.08 & 0.06 & 0.01 & 0.07 & 0.02 & 0.10 \\
\hline \multicolumn{7}{|l|}{ Child's maturation } \\
\hline Age & -0.00 & 0.00 & 0.01 & 0.07 & 0.00 & 0.01 \\
\hline Parental status & $-0.12 *$ & 0.05 & $-0.20 * *$ & 0.07 & $-0.34 * *$ & 0.09 \\
\hline Employment & 0.03 & 0.06 & 0.03 & 0.11 & 0.05 & 0.14 \\
\hline Contact with mother & 0.02 & 0.02 & 0.03 & 0.03 & 0.05 & 0.03 \\
\hline Favoritism in childhood & 0.01 & 0.02 & -0.02 & 0.03 & 0.01 & 0.04 \\
\hline \multicolumn{7}{|l|}{ Mother's characteristics } \\
\hline Race & -0.08 & 0.08 & 0.10 & 0.13 & 0.13 & 0.15 \\
\hline Number of children & $0.06 * *$ & 0.01 & $-0.07 * *$ & 0.02 & $-0.07 * *$ & 0.03 \\
\hline Model $R^{2}$ & \multicolumn{2}{|c|}{0.05} & \multicolumn{2}{|c|}{0.08} & \multicolumn{2}{|c|}{0.07} \\
\hline$d f$ & \multicolumn{2}{|c|}{12} & \multicolumn{2}{|c|}{12} & \multicolumn{2}{|c|}{12} \\
\hline$F$ & \multicolumn{2}{|c|}{$2.44 * *$} & \multicolumn{2}{|c|}{$2.60 * *$} & \multicolumn{2}{|c|}{$2.41 *$} \\
\hline$n$ & \multicolumn{2}{|c|}{676} & \multicolumn{2}{|c|}{411} & \multicolumn{2}{|c|}{408} \\
\hline
\end{tabular}

Note. The $n$ of cases in Models 2 and 3 differ from that in Model 1 because Models 2 and 3 include only cases in which mothers did choose a particular child, whereas Model 1 also

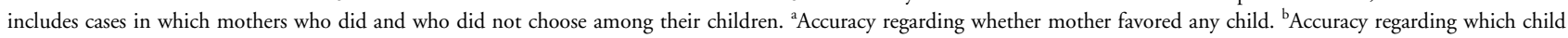
mother favored. 'Accuracy regarding whether mother favored and which child mother favored.

${ }^{\dagger} p<.10 .{ }^{*} p<.05 . * * p<.01$. 
whereas those who were the least accurate were those who were parents and who had a larger number of siblings.

In summary, the multivariate analyses of reporting discrepancies revealed some clear patterns. The most consistent finding was the effect of parenthood on adult children's accuracy of reporting their mothers' stated preferences. The reports of adult children who were parents were substantially less likely to reflect their mothers' reports than were those who were childless, irregardless of whether their mothers expressed favoritism and which children they chose. Similarity of religious participation was also a predictor of children's reporting accuracy - children whose religious attendance matched that of their mothers were more likely to accurately report which children the mothers named as being closest to emotionally or in which they would confide. Finally, family size was also a predictor of children's accuracy of reporting, albeit in different directions depending on the issue under consideration. Children with a larger number of siblings were more likely to accurately report whether their mothers favored particular children in the family, but they were less able to accurately identify the favored children. Contrary to expectations, we were unable to predict which adult children were most likely to accurately report mothers' favoritism in any single context; we believe this can be explained by the fact that there was relatively little incongruence between mothers and children in any single context.

\section{Discussion}

These findings shed light on an increasingly important issue-parental favoritism in later life families (Boll, Ferring, \& Filipp, 2003; Suitor \& Pillemer, 2006; Suitor et al., 2006). To our knowledge, the present study is unique in its focus on the extent of parental preference toward adult children through the use of reports from both generations.

As shown in previous analyses, which were based on mothers' reports alone (Suitor et al., 2006), more than two-thirds of mothers were able to select a child to whom they were most emotionally close, and more than $80 \%$ specified a child whom they preferred as a confidant. Considering that pressures toward social desirability are likely to have inhibited some respondents from reporting a preference they actually held, these findings indicate substantial differentiation among offspring. Further, given that mothers may well have attempted to shield their favoritism from their offspring, it is remarkable that the children demonstrated such a high level of awareness of the unequal distribution of parental affect. However, adult children were not as accurate as one might expect regarding maternal favoritism, considering their level of consciousness regarding the existence of favoritism. Less than half of the children correctly identified the child to whom their mother was most emotionally close, and only a little more than half accurately reported the child in whom their mother was most likely to confide. The children's statements about their perceptions of mothers' favoritism indicated that those who actually were accurate in their reports of mothers' stated preference were no more confident in their statements than were those whose reports were inaccurate. In fact, the children whose reports were inaccurate were often more emphatic in their statements regarding both whether their mothers favored some offspring and which specific offspring were favored.

Multivariate analyses of the congruence in children's and mothers' reports of favoritism revealed no consistent patterns when examining each relational context separately; however, clear patterns emerged when using measures of the extent of children's accuracy in reporting. Congruence was predicted by similarity of religious participation, parenthood, and family size. Specifically, adult children who were similar to their mothers in religious participation were more likely to accurately report their mothers' preferences, whereas children who were parents were less likely to provide accurate reports. Family size predicted children's accuracy of reporting, although the direction of effects varied by relational context; children from larger families more accurately reported whether their mothers favored particular children in the family but less accurately identified the particular favored children.

The finding that parenthood reduced the likelihood that adult children would accurately report their mothers' stated preferences contributes to a growing literature suggesting that the attainment of normative adult statuses may decrease rather than increase intergenerational contact and closeness. Studies from the 1950s through the 1980s generally showed that mothers' and children's closeness and contact increased when children married and became parents (Fischer, 1986; Young \& Willmott, 1957). However, more recent studies have found 
that the attainment of such adult statuses often reduces contact, closeness, and intergenerational exchanges of support (Gerstel \& Sarkisian, in press; Suitor et al., 2006). We suggest that this change in the effect of marital and parental status on intergenerational relations may reflect the fact that as women's employment has become normative, adult children, particularly daughters, find themselves more pressed for time (Hochschild, 1997) and less able to maintain high levels of interaction. If this is the case, adult children may also be more distracted, thus reducing their sensitivity to intergenerational family processes. It is also worth noting that this may not be only when adult children are raising minor children; research has also demonstrated that parenting often continues to make demands on individuals, even after their children reach adulthood (Cohler \& Grunebaum, 1981; Pillemer \& Suitor, 1991, 2005).

The effect of religious participation on intergenerational reporting congruence is intriguing. Although a small number of studies have shown that similarity of religious participation plays a role in parent-adult child relations (Myers, 2004; Pearce \& Axinn, 1998; Rossi \& Rossi, 1990), this factor is seldom included in intergenerational research. The findings we have reported here combined with those of other researchers (e.g., Myers; Pearce \& Axinn; Rossi \& Rossi) suggest that this dimension of similarity should be given greater attention in the literature.

\section{Implications for Research}

The most obvious implication of this study is the need to obtain data from both members of parentchild dyads in studies of quality of older parentadult child relationships. This insight is of course well-known to clinicians and case workers involved with aging families but has not extensively permeated research on parent-child relations. Indeed, several analysts have argued that family gerontology should embrace the concept of multiperspectivity as a tenet of research (Luescher \& Pillemer, 1998; Pillemer \& Suitor, 1998, 2005). Given that discrepancies exist revolving around features as central to relationships as closeness and confiding, it is likely that each family member's perspective is to some degree unique because of his or her niche in the family (Pillemer \& McCartney, 1991).
Second, this study suggests the need for additional qualitative research on within-family differentiation in later life. In particular, in-depth interviews and observations are needed to better understand why some children are aware of mothers' preferences and others are not. We suspect that we may not have captured the more subtle nuances of family life that communicate favoritism, beyond those of developmental events and similarity in social structural characteristics and attitudes. Given that we have demonstrated the prevalence of favoritism in later life families, this appears to be fertile ground for in-depth, qualitative studies.

Third, an obvious step for future research is examining patterns of preference, and children's awareness of such patterns, among fathers. It is possible that the extent and dynamics of favoritism, as well as discrepancies in identifying it, will differ between father-child and mother-child dyads.

Fourth, it is important that future studies address the consequences of parental favoritism for both adult children and their parents. Some research has indicated that experiencing favoritism has negative consequences for offspring, such as resentment and lowered self-esteem (Bedford, 1992). Given the prevalence of parental preference for specific children demonstrated in this study, further examination of its effects is recommended.

\section{Implications for Practice}

In this study, we have provided empirical data on a phenomenon that family practitioners may observe among their clients_-parental preference for specific adult children along key socioemotional dimensions. The findings suggest that patterns of actual parental preference, as well as perceived preference by children, are widespread. However, although adult children are often correctly aware that their mothers have a preferred child, they are frequently unable to accurately identify which child is preferred. There are several implications of these findings for practitioners working with older persons and their families.

There has been considerable growth in family therapy approaches to families in later life (Fine \& Norris, 1989; Qualls, 2000). It is useful in this context for family therapists to be aware of the fact that despite norms for equal treatment of children, older mothers typically differentiate among their children. 
It is likely that issues of parental favoritism will emerge in therapeutic contexts, and clinicians can have some confidence that adult children's concerns or complaints in this regard have considerable basis in reality. However, when attention turns to the sibling configuration, adult children often misidentify the actual favorite child. It is possible that mothers are effective in disguising preference or that adult children use different criteria from mothers in identifying a favored child. Regardless of the cause, the results of the present study demonstrate that differentiation within the family in later life is a reality and one that may need to be addressed by those who work with parents and adult children. Indeed, for families struggling with issues related to sibling perceptions of unfairness or inequality, it may be reassuring to realize that such differentiation is normative rather than unusual.

These insights are also likely to be useful for community agencies (e.g., Area Agency on Aging, Cooperative Extension, hospitals) that sponsor educational programs on the topic of the aging family. Because of the powerful norm of equal treatment of offspring in families, and perhaps because favoritism may be considered a "taboo" topic, education programs rarely address the issue of real or perceived parental preference. Family life education that involves older persons may wish to include the issue of patterns of within-family preference on the part of parents, as well as the way in which adult children perceive such patterns. Understanding the correlates and dynamics of parental preference may relieve anxiety over this issue in both generations and encourage greater family discussion.

Further, there are potential implications of the discrepancies we found for planning for the eventuality of mothers' care and assistance. Care planning with older mothers and their adult children should include attempts to reach a shared understanding of the mothers' preferences, as well as working with adult children toward the acknowledgement and acceptance of such preferences. Given that the vast majority of mothers have clearly stated preferences for certain children, family practitioners, family therapist, and other professionals who work with later life families may need to help adult children clarify such preferences as care needs begin to arise. Mothers may expect care from certain offspring, while those children themselves may expect other siblings who are perceived to be favored to take on such responsibility. Research suggests that if one child in the family is expected to provide care, the other siblings reduce their anticipated caregiving commitments (Neuharth \& Stern, 2002). Understanding patterns of mothers' preference and discrepancies with children's perceptions may help prevent family conflict over caregiving from arising. Caregiver education programs increasingly include a component on the parent's preferences for care and on the expectations of offspring; such training could take issues of favoritism into account (FoxGrage \& Gibson, 2006).

\section{References}

Alessandri, S. M., \& Wozniak, R. W. (1987). The child's awareness of parental beliefs concerning the child: A developmental study. Child Development, 58, 316-323.

Aquilino, W. S. (1999). Two views of one relationship: Comparing parents' and young adult children's reports of the quality of intergenerational relations. Journal of Marriage and the Family, 61, 858-870.

Arcana, J. (1981). Our mothers' daughters. London: The Women's Press.

Bedford, V. H. (1992). Memories of parental favoritism and the quality of parent-child ties in adulthood. Journal of Gerontology: Social Sciences, 47(4), S149-S155.

Bengtson, V. L. (2001). Beyond the nuclear family: The increasing importance of multigenerational bonds. Journal of Marriage and the Family, 63, 1-16.

Bengtson, V. L., \& Kuypers, J. A. (1971). Generational difference and the developmental stake. Aging and Human Development, 2(1), 249-260.

Bengtson, V. L., \& Roberts, R. E. L. (1991). Intergenerational solidarity in aging families: An example of formal theory construction. Journal of Marriage and the Family, 53, 856-870.

Boll, T., Ferring, D., \& Filipp, S. H. (2003). Perceived parental differential treatment in middle adulthood curvilinear relations with individuals' experienced relationship quality to sibling and parents. Journal of Family Psychology, 17, 472-487.

Burg, M. M., \& Seeman, T. E. (1994). Families and health: The negative side of social ties. Annals of Behavioral Medicine, 16, 109-115.

Cashmore, J. A., \& Goodnow, J. J. (1985). Agreement between generations: A two-process approach. Child Development, 56, 493-501.

Chodorow, N. J. (1978). The reproduction of mothering. Berkeley: University of California Press.

Cleese, A. F., \& Bates, B. (2003). How to manage your mother: Understanding the most difficult, complicated, and fascinating relationship in your life. New York: Gardeners Books.

Cohler, B. J., \& Grunebaum, H. (1981). Mothers, grandmothers, and daughters. Personality and childcare in three-generation families. New York: Wiley.

Coser, R. L. (1991). In defense of modernity: Role complexity and individual autonomy. Stanford, CA: Stanford University Press.

Feld, S. L. (1982). Social structural determinants of similarity among associates. American Sociological Review, 47, 797-801.

Fine, M., \& Norris, J. E. (1989). Intergenerational relations and family therapy research: What we can learn from other disciplines. Family Process, 28, 301-315.

Fischer, L. R. (1986). Linked lives: Adult daughters and their mothers. New York: Harper \& Row.

Fox-Grage, W., \& Gibson, M. J. (2006). Ahead of the curve: Emerging trends and practices in family caregiving support. Washington, DC: AARP Public Policy Institute.

Gerstel, N., \& Sarkisian, N. (in press). Marriage: The good, the bad, and the greedy. Contexts.

Giarrusso, R., Stallings, M., \& Bengtson, V. L. (1995). The intergenerational stake hypothesis revisited: Parent-child differences in perceptions 
of relationships 20 years later. In K. W. Schaie, V. L. Bengtson, \& L. M. Burton (Eds.), Adult intergenerational relations: Effects of societal change (pp. 227-263). New York: Springer.

Gilligan, C. (1982). In a different voice: Psychological theory and women's development. Cambridge, MA: Harvard University Press.

Gouldner, H., \& Strong, M. S. (1987). Speaking of friendships: Middle-class women and their friends. Westport, CT: Greenwood Press.

Hochschild, A. R. (1997). Time bind: When work becomes home and home becomes work. New York: Henry Holt \& Company.

King, D. A., \& Wynne, L. C. (2004). The emergence of 'family integrity' in later life. Family Process, 43(1), 7-21.

Lazarsfeld, P. F., \& Merton, R. K. (1954). Friendship as a social process: A substantive and methodological analysis. In M. Berger, T. Abel \& C. H. Page (Eds.), Freedom and control in modern society (pp. 18-66). New York: Litton.

Luescher, K., \& Pillemer, K. (1998). Intergenerational ambivalence: A new approach to the study of parent-child relations in later life. Journal of Marriage and the Family, 50, 775-783.

Maas, C. J. M., \& Hox, J. J. (2004). Robustness issues in multilevel regression analysis. Statistica Neerlandica, 58, 127-137.

Martire, L. M., Stephens, M. A. P., Druley, J. A., \& Wojno, W. C. (2002). Negative reactions to received spousal support: Predictors and consequences of miscarried support. Health Psychology, 21(2), 167-176.

McBroom, W. H., Reed, F. W., Burns, C. E., Hargraves, L. L., \& Trankel, M. A. (1985). Intergenerational transmission of values: A data-based reassessment. Social Psychology Quarterly, 48(2), 150-163.

McPherson, M., Smith-Lovin, L., \& Cook, J. M. (2001). Birds of a feather: Homophily in social networks. Annual Review of Sociology, 27, 415-444.

Myers, S. M. (2004). Religion and intergenerational assistance: Distinct differences by adult children's gender and parent's marital status. The Sociological Quarterly, 45(1), 67-89.

Neuharth, T. J., \& Stern, S. (2002). Shared caregiving responsibilities of adult siblings with elderly parents. Journal of Human Resources, 37, $441-478$.

Nice, V. E. (1992). Mothers and daughters: The distortion of a relationship. New York: St. Martin Press.

Pascarella, E. T., \& Terenzini, P. T. (1991). How college affects students. San Francisco: Jossey-Bass.

Pearce, L. D., \& Axinn, W. G. (1998). The impact of family religious life on the quality of mother-child relations. American Sociological Review, $63,810-828$.

Pillemer, K., \& McCartney, K. (Eds.). (1991). Parent-child relations throughout life. New York: Erlbaum.

Pillemer, K., \& Suitor, J. J. (1991). Will I ever escape my child's problems? Effects of adult children's problems on elderly parents. Journal of Marriage and the Family, 53, 585-594.

Pillemer, K., \& Suitor, J. J. (1998). Baby boom families: Relations with aging parents. Generations, 12(1), 65-69.

Pillemer, K., \& Suitor, J. J. (2005). Ambivalence in intergenerational relations over the life-course. In M. Silverstein (Ed.), Annual review of gerontology and geriatrics: Vol. 2. Intergenerational relations across time and place (pp. 3-28). New York: Springer.
Pruchno, R., Burant, C., \& Peters, N. D. (1994). Family mental-healthMarital and parent-child consensus as predictors. Journal of Marriage and the Family, 56, 747-758.

Qualls, S. H. (2000). Therapy with aging families: Rationale, opportunities and challenges. Aging \& Mental Health, 4, 191-199.

Rossi, A. S., \& Rossi, P. H. (1990). Of human bonding: Parent-child relations across the life course. New York: Aldine de Gruyter.

Ryff, C. D., Schmutte, P. S., \& Lee, Y. H. (1996). How children turn out: Implications for parental self-evaluation. In C. D. Ryff \& M. M. Seltzer (Eds.), The parental experience in midlife (pp. 383-423). Chicago: University of Chicago Press.

Silverstein, M., \& Bengtson, V. (1997). Intergenerational solidarity and the structure of adult child parent relationships in American families. American Journal of Sociology, 103, 429-460.

Suitor, J. J. (1987). Mother-daughter relations when married daughters return to school: Effects of status similarity. Journal of Marriage and the Family, 49, 435-444.

Suitor, J. J., \& Keeton, S. (1997). Once a friend, always a friend? Effects of homophily on women's support networks across a decade. Social Networks, 19(1), 51-62.

Suitor, J. J., \& Pillemer, K. (2006). Choosing daughters: Exploring why mothers favor adult daughters over sons. Sociological Perspectives, 49(2), $139-160$.

Suitor, J. J., Pillemer, K., \& Keeton, S. (1995). When experience counts: The effects of experiential and structural similarity on patterns of support and interpersonal stress. Social Forces, 73, 1573-1588.

Suitor, J. J., Pillemer, K., Keeton, S., \& Robison, J. (1995). Aged parents and aging children: Determinants of relationship quality. Westport, CT: Greenwood Press/Greenwood Publishing Group.

Suitor, J. J., Pillemer, K., \& Sechrist, J. (2006). Within family differences in mothers' support to adult children. Journal of Gerontology: Social Sciences, 16B, S10-S17.

Sweet, J. A., \& Bumpass, L. L. (1996). The national survey of families and households waves 1 and 2: Data description and documentation. University of Wisconsin Madison, Center for Demography and Ecology.

Szinovacz, M. E., \& Davey, A. (2001). Retirement effects on parent-adult child contact. The Gerontologist, 41, 191-200.

Tein, J., Roosa, M. W., \& Michaels, M. (1994). Agreement between parent and child reports on parental behaviors. Journal of Marriage and the Family, 56, 341-355.

Thoits, P. A. (1986). Multiple identities: Examining gender and marital status differences in distress. American Sociological Review, 51(2), 259-272.

Wellman, B., \& Wortley, S. (1990). Different strokes from different folks: Community ties and social support. American Journal of Sociology, 93, $558-588$.

Welsh, W. M., \& Stewart, A. J. (1995). Relationships between women and their parents: Implications for midlife well-being. Psychology and Aging, 10(2), 181-190.

Young, M., \& Willmott, P. (1957). Family and kinship in east London. Glencoe, IL: Free Press.

Youngblade, L. M., \& Shenkman, E. A. (2003). Congruence between parents' and adolescents' reports of special health care needs in a title XXI program. Journal of Pediatric Psychology, 28, 393-401. 